\title{
Business intelligence addressing service quality for big data analytics in public sector
}

\author{
Sadesh Manikam $^{1}$, Shamsul Sahibudin², Vinothini Kasinathan ${ }^{3}$ \\ 1,2 Advanced Informatics School (AIS), Universiti Teknologi Malaysia, Malaysia \\ ${ }^{3}$ School of Computing, Asia Pacific University of Technology and Innovation, Taman Teknologi Malaysia, Malaysia
}

\begin{tabular}{|c|c|}
\hline Article Info & ABSTRACT \\
\hline Article history: & \multirow{11}{*}{$\begin{array}{l}\text { With the inauguration of Big Data Analytics initiative nationally, many } \\
\text { nations have participated and paved way for BDA ecosystem. The initiative } \\
\text { is a catalyst to further encourage economic growth in Public Sectors. Some } \\
\text { of the common key deliverables identified are increasing productivity } \\
\text { involving information communications technology, cost savings, shared } \\
\text { benefits, and encourage innovation. The objectives can be further elaborated } \\
\text { by driving big data analytics demands in various public sectors agency, } \\
\text { adopting big data analytics framework supporting the building of big data } \\
\text { industry. This has encouraged talents and startup companies inspiring their } \\
\text { capabilities by developing various technology platform, collaborate and } \\
\text { innovate amongst public and private sectors, and further strengthen data } \\
\text { governance by creating policy and procedures. With the establishment of big } \\
\text { data analytics framework, performance measurement can be enforced } \\
\text { effortlessly using the principles of business intelligence maturity model and } \\
\text { the technological stack comes with it. Various data sources can be used to } \\
\text { benchmark service quality using advanced analytics and data science } \\
\text { techniques. }\end{array}$} \\
\hline Received Jan 9, 2019 & \\
\hline May 1, 2019 & \\
\hline Accepted May 27, 2019 & \\
\hline Keywords: & \\
\hline Big data analytics & \\
\hline Digital enterprise & \\
\hline Digital metrics & \\
\hline Performance management & \\
\hline Business intelligence & \\
\hline Service quality & \\
\hline
\end{tabular}

Copyright @ 2019 Institute of Advanced Engineering and Science. All rights reserved.

\section{Corresponding Author:}

Sadesh Manikam,

Advanced Informatics School (AIS),

Universiti Teknologi Malaysia, Malaysia.

Email: ijeecs.iaes@gmail.com

\section{INTRODUCTION}

The world is being digitally transformed; the wave has redefined customer and business expectations driven by rapid emerging technologies [1]. Digital transformation, has immense the potential to change consumer lives and create value for business [2]. Enriched decision making, speed to market, improved service quality and increased revenue are some of the benefits contributing since the inauguration of big data implementation across enterprises [3]. The World Economic Forum describes the data garnered by big data as "the new 'oil'-a valuable resource of the 21 st century. "Big data analytics is the "new engine of economic and social value creation" [1].

Over the last two decades, Fourth Industrial Revolution (Industry 4.0) has signify the vast increased in availability of information, decision-makers from the public and private sectors are confronted with a new set of uncertainties regarding the future of production $[1,4]$. Under the right circumstances, decision-makers will be able to manage and capitalize on imminent transformations [1, 3, 4]. The introduction of digital revolution by Industry 4.0, has already begun transforming companies and industries into digitalizing across multi facets of business, providing unparalleled opportunities to use data in an enterprise scale. Meantime, constant evolving Digital Enterprise requires Big Data Analytics to provide a platform for large enterprise volume of data set [5] for measuring digital traction metrics.

With Digital transformation on the rise, many enterprises has discovered the traditional way of measuring critical success factor are less effective evaluating the success of a business. Digital traction 
metrics provides invaluable insights which complements analytic, and it further drives the businesses for using Net Promoter Score (NPS) to measure the engagement of customer against the traditional service quality measurement $[3,6]$. The metrics provides an avenue for the public sectors to perform valuation on customer satisfaction and pronouncing investment in economics for public enterprise.

Although overall economic freedom continues to be constrained by systemic shortcomings that damage prospects for more vibrant long-term economic expansion; Public Sector has evolving requirements for utilizing Big Data Analytic, with the recent strategic economic reforms [6, 16-20]. Now with the introduction of Digital Enterprise and Big Data Analytics, the requirements has lead transforming yesterteachings and learning by improving the ability to extract knowledge and obtain insights from large and complex collections of digital data.

\section{EVOLUTION OF BUSINESS INTELLIGENCE TO BIG DATA ECOSYSTEM}

Big data applies to information that ant be processed or analyzed using traditional process or tools. Many organizations today are facing more and more Big Data challenges although they have acquired abundance of information but it is unfortunate for not able to fully make use of those information attained [17]. With the implementation of "smart cities" by many of the Developed Economy countries, vast data are collected in the form of Internet of Things, (IOT) [7]. Monitoring and emitting the data stream [8] from the status of streetlights, parking facilities, automatic garage gates, and other field equipment are used to improve roads, reduce traffic congestion, and enhance public transportation options [7, 9]. A predictive intelligence model are built to analyze real-time data stream to react against the demand.

Emergence of Big Data in 2011 as the leading chapter in Business Intelligence and Analytics [6], it was represented unusual data source (e.g., sensors, social media, streaming data, video and voice) [20] which is classified as semi-structured and unstructured data [17]. Advanced technologies such as, Hadoop architectures, visualization, predictive and prescriptive analytics) [20], and with combinations of professional skills (e.g., Data Administrator, Data Analysts, Data Engineer and Data Scientists) [17, 23, 21] are required to be able to make sense out of the data and building block for insights [10]. Figure 1, illustrates the High Level Big Data Architecture [11], meanwhile WO Chang describes, Figure 2 describes the National Institute of Standards and Technology-Standard Enterprise Big Data Ecosystem, (June 19, 2017) [12].

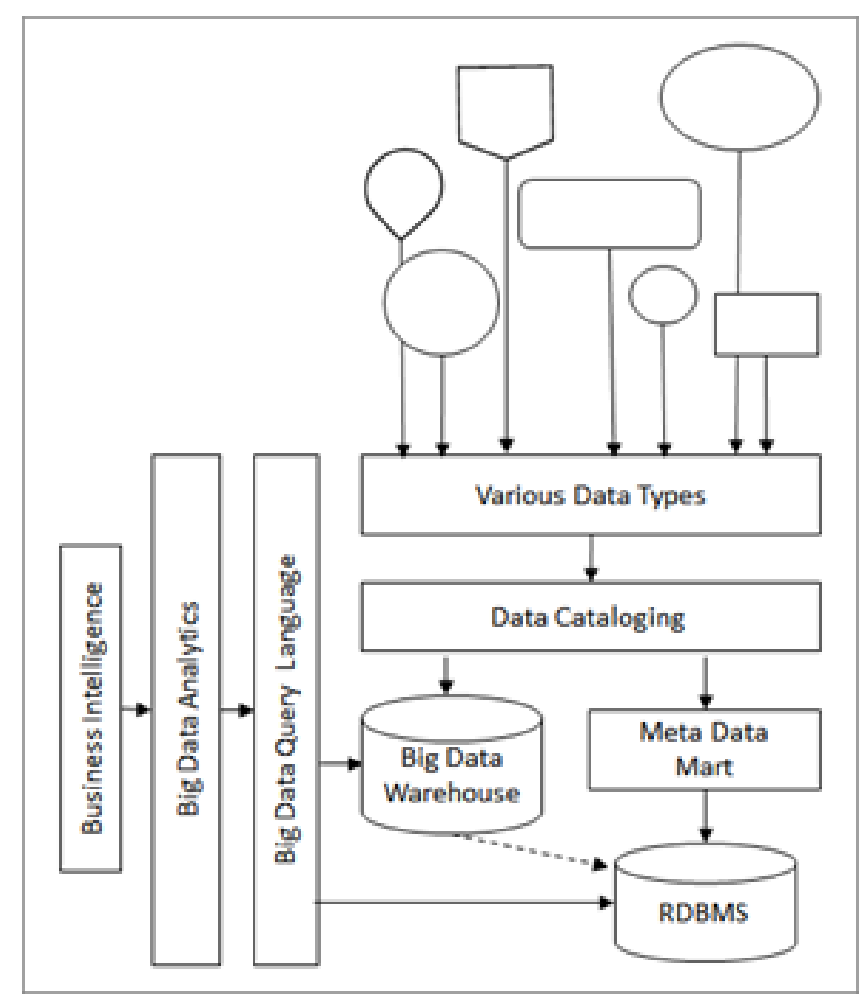

Figure 1. High level big data architecture adopting business intelligence techniques 


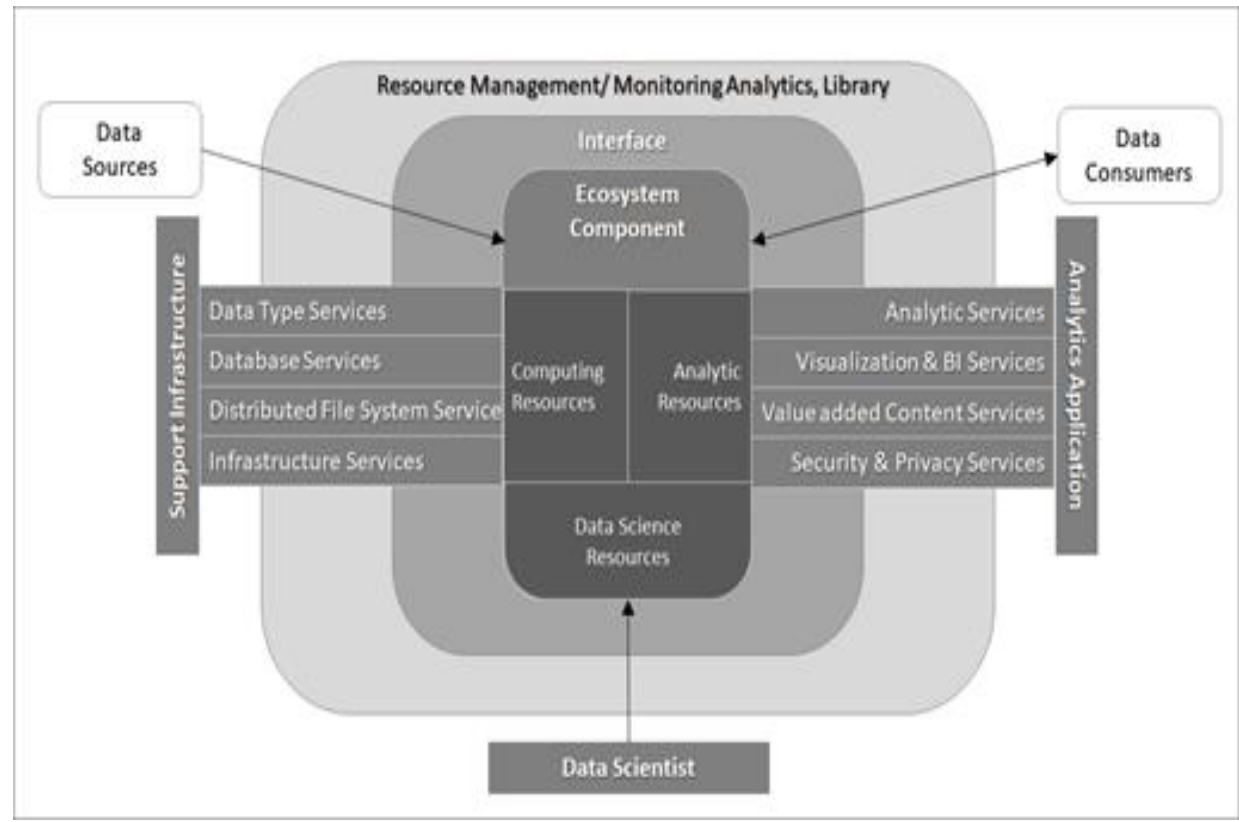

Figure 2. Digital enterprise adopting the NIST standard enterprise big data ecosystem

\section{ADOPTING B1 DATA QUALITY IN BIG DATA FRAMEWORK}

Big Data Analytics being the most discussed topic in the Business Intelligence space [22], this is because the core data mining and analytics was defined during the early stage of business intelligence framework [23, 25]. Gartner's definition is the most widely used: "Big Data is high-volume, high-velocity and high variety information assets that demand cost-effective, innovative forms of information processing for enhanced insight and decision making' [40]. The ultimate aim of Business Intelligence model is to provide accurate insights with relevant information, to help an organization to have comprehensive information impacting the business. BI is an interactive computer-based structures with subsystems intended to ease decision makers using data, documents, knowledge, analytical and predictive models to identify and justify the problems tangibly [24]. BI application offers the potential for significantly improving operational and strategic performance for organizations of various sizes and types.

Although BI technologies provide historical, current and predictive views of business operations. The credibility of business intelligence technologies is providing analytical reporting from online analytical processing (OLAP) cubes [6]. Meanwhile more complex analytics, data mining and process mining, complex event processing, business performance management, benchmarking, text mining, predictive analytics, prescriptive analytics and machine learning [25], deep learnings can be achieved from data science space. There are several points to be consider before raw data from online transaction processing (OLTP) and other sources of data being feed into the data warehouse [6]. During the transformation process either ExtractTransform-Load (ETL) or Extract-Load-Transform, (ELT), data quality will be comprehended and data reliability will be at stake. To ensure Data Quality are adhered before the data are transformed and loaded into OLAP cubes, data modelling and data profiling to be executed to identify data condition before and after it transformed using business rules. The transform rules specifications leads an amendment of validation rules explicitly and implicitly implemented in the ETL/ELT process [26]. To ensure high data quality, the ETL/ELT pipelines has to handle exceptions so that data quality will improve [27] and retains at high quality.

Data Quality is expected to deliver an adequate characterization of data, right interpretation of results, data visualization, real-time view of data vs. retrospective view and determining the relevance of results of projects. With these challenges, Data Quality takes a decisive part in the sense of addressing the trustworthiness of input data.

Although there are several standards assess the best practices for data quality, such as ISO/IEC 25000 is the family of standards addressing Systems and Software Quality Requirements and Evaluation (SQuaRE). It provides several divisions: ISO/IEC 2500n — Quality Management, ISO/IEC 2501n — Quality Model, ISO/IEC 2502n-Quality Measurement, ISO/IEC 2503n-Quality Requirements, and ISO/IEC 2504n-Quality Evaluation. Meanwhile Data Quality-in-Use model for Big Data is generally bounded around the standards of ISO/IEC 25012 [41] and ISO/IEC 25024 [42]. 


\subsection{ISO/IEC 25012}

ISO/IEC 25012 [41] gathers the main desirable Data Quality characteristics for any dataset. In [41], Data Quality is described using a defined external Data Quality model. The Data Quality model defined in [41] categorizes quality attributes into fifteen characteristics considered by two points of view:

a) Inherent Data Quality refers to the degree to which quality characteristics of data have the intrinsic potential to satisfy stated and implied needs when data is used under specified conditions.

b) System dependent Data Quality refers to the degree to which Data Quality is reached and preserved within a computer system when data is used under specified conditions.

The categorization of the Data Quality characteristics according to these points of view is depicted in Table 1. The reliability and accuracy is direct proportionate to data quality, thus data quality is the prime contributor to measure critical success factor to represent the Key Performance Indicator (KPI).

Table 1. Characteristics of data quality categorization according to inherent vs system dependent

\begin{tabular}{lcc}
\hline Characteristic & Inherent & System dependent \\
\hline Accuracy & $\mathrm{X}$ & \\
Completeness & $\mathrm{X}$ & \\
Consistency & $\mathrm{X}$ & \\
Credibility & $\mathrm{X}$ & \\
Currentness & $\mathrm{X}$ & \\
Accessibility & $\mathrm{X}$ & $\mathrm{X}$ \\
Compliance & $\mathrm{X}$ & $\mathrm{X}$ \\
Confidentiality & $\mathrm{X}$ & $\mathrm{X}$ \\
Efficiency & $\mathrm{X}$ & $\mathrm{X}$ \\
Precision & $\mathrm{X}$ & $\mathrm{X}$ \\
Traceability & $\mathrm{X}$ & $\mathrm{X}$ \\
Understandability & $\mathrm{X}$ & $\mathrm{X}$ \\
Availability & & $\mathrm{X}$ \\
Portability & & $\mathrm{X}$ \\
Recoverability & & $\mathrm{X}$
\end{tabular}

\subsection{ISO/IEC 25024}

ISO/IEC 25024 [41] defines some basics and concepts that allow to perform objective and unbiased Data Quality measurements. Figure 1 shows the main concepts of ISO/IEC 25024 and their relationships. For a deeper knowledge about those concepts see [42]. In this way, one or more Quality Measures can be used for the measurement of a Data Quality characteristic, [42] establishes Quality Measures for the characteristics included in the Data Quality model defined in [41]. The Quality Measures described in [42] are quantifications of the Data Quality characteristics, and those concerning data can be used over all the stages of the Data-Life-Cycle and for other processes, for example:

a) To establish Data Quality requirements.

b) To evaluate Data Quality.

c) To support and implement data governance, data management, data documentation process.

d) To support and implement IT services management processes.

e) To support improvement of Data Quality and effectiveness of business decisions process.

f) To benchmark Data Quality of different data management solutions during investigation process.

g) To evaluate the quality of system and/or software components that produce data as an outcome.

Data Quality model allows a company to assess if the data is governed by Big Data Quality. Thus the best practices is presented by Data Quality-in-Use model from Big Data. It is largely grounded by the standards of ISO/IEC 25012 [41] and ISO/IEC 25024 [42].

\section{MEASURING SERVICE QUALITY USING PERFORMANCE MANAGEMENT TECHNIQUES}

Measuring service quality in the private sector has been one of the critical success factor for both enterprise performance and customer satisfaction [15]. The increasing customer demands for personalized services in public sector are likely to meet expenditure gaps [13]. With the proper definition and enforcement of organization KPI, a cluster of metrics are to be used to measure the goals against the strategy of an enterprise, through metrics-driven management [29]. The measure of service quality, assess the potential of the quality of the service instrument for the public sector and report on an application of the instrument to a public library services [15]. 
By using the instruments from the vast evolving technology, supporting day-to-day operations, compliances and service quality could be further strengthen [13]. With the implementation of metrics driven management, the instrument is capable to record transactions, manage operational processes, automate compliance and controls, as well as indicates the service quality of an enterprise [28] by providing the reporting streams. These reports display the critical success factor representing KPIs as the metrics as a performance management benchmark [14]. The data obtained can be represented, either for numerical or visualization analytics. The data presentation will be used as a logical end point for any BI system and becomes the source of insights for to improve service quality and make decision on the action plan. According to Zaherawati [29] there are three main KPIs found for Public Enterprise, mainly:

a) Effectiveness and the efficiency of the internal work process to deliver the services.

b) Measure the productivity of human resources to provide and deliver services to customers

c) Measure the customer satisfaction towards services received

Traditional the criticism can be narrow and easily quantifiable by performance measurement on the lack of neutrality [29]. With metrics driven management, a re-appraisal of biasness towards the development of performance measurement using balanced score card. As a result, organizations and enterprises has started to develop key performance indicator strategy instrumenting the business intelligence in performance measurement systems i.e. Balance Scorecard, Benchmarking, Continuous Improvement, Total Quality Management, Management by Objectives and Quality Control Circle.

\section{SERVICE QUALITY FOR BDA REQUIREMENTS}

Nasab S. has identified critical success factor for business intelligence implementation in various public enterprise [30] which measures the services programs if it is more or less effective [31]. Some of the identifying requirements are described in Table 1. Large organization including public enterprise are constantly assessing how to manage volume, variety and velocity of the untapped information in effort to exploit critical decisions $[17,34,40]$. With the current agility requirements real time analytics is required in providing critical insights towards catastrophe advantage.

\section{1. e-Government and politics}

Digital transformation has encourage public and private web hosting sites to be more user friendly and provide the information [1] a person wants to see. Traditionally users will search for the information, but with the digital transformation ecosystem in place, predictive intelligence are implemented to provide information to users before one could even start searching [28]. Web engines nowadays are intelligent to understand the consumer search pattern before representing the personalized information on the screen. Providing the capability to analyze, compare, decide against the real time insights has been some of the expectation from the consumers.

Some of the initiative taken by the public sector modernization of e-government is on the political campaign. The participation process has undergone a major transformation [28] recently, service quality provide to the citizens are being constantly benchmark. The first Internet voting took place in 2000, CNN hosted the first YouTube debates in 2007, and in 2008 Barack Obama launched a highly mobile and successful Internet-based presidential campaign. Cambridge Analytica provided the Donald J. Trump for President Campaign with the expertise and insights that helped win the White House [47].

Service quality are being measure online and instant reaction are being published to manage the perception and the confidence of the citizens [28] and provide a statistical probability identify "persuadable" voters, how likely they were to vote [47]. The US Government's meticulous process of "going electronic", was a good indication of mitigating citizen expectation towards the challenges facing by the government [28].

\subsection{Public health services}

Digitalization of healthcare information has been always a critical success indicator to understand possibilities for health and social care service providers to enhance the quality of care [26], improve healthcare outcomes, and reduce costs [45]. The exponential demand in healthcare industry requires many Hospital and Clinical Information System to repositioning their tools to allow for healthcare-specific analytical capabilities. Healthcare analytics provide methods and processes for extracting and transforming raw medical data [26, 44], and patient information into meaningful insight to support efficient and effective healthcare decisions.

Meanwhile the constant efforts of improving customer quality of service, by integrating social, demographic, environmental, and behavioral information [26] allows the discovery of new patterns that might otherwise have remained hidden. This analysis will be used as an instrument to measure the indicator 
as the key driver to transform the provision of health and social care services. Increase in the service quality will encourage the empowerment of patients in managing their own health; fostering efficiency, quality of care and sustainability of health and social care systems [46]

\subsection{Science and technology}

Nowadays, big data analytics for geospatial data is receiving sizeable attention and allowing users to analyze huge amounts of geospatial data. Geospatial big data typically refers to spatial data sets exceeding capacity of current computing system [27]. Location targeting is known to improve the performance of mobile advertising by over $200 \%$. Geosocial networking services, performs mobile advertising when a user connects to the services. The services will provide locations which are closer to the Global Positioning System (GPS) location [50].

Similarly the meteorological department will also provide predictive intelligence over the potential natural disaster such as hurricane, tsunami and typhoon. Broadcasting the information over web portal provide the users the confidence of the data for catastrophe preparation [50].

\subsection{Security and public safety}

The delivery of consistent service quality is arguably the most vital factors that contribute to the establishment of credibility and reputation of the organizations in the eyes of the public. Municipal authorities, faces more daunting tasks than those in the private sector in their efforts to provide excellent service and maintain citizen satisfaction [48]. Efficient and effective delivery system becomes the main focus of the government of many countries due to insistence and hopes from society for local authorities giving their services up to the quality standard as expected by the tax payers [48].

"Smart cities" by many of the nations has already collecting large volume of data in the form of Internet of Things, (IOT) [7]. These data stream will be used to monitoring and emitting the status of streetlights, parking facilities, automatic garage gates [8], and other field equipment are used to improve roads, reduce traffic congestion, and enhance public transportation options [7,9]. A predictive intelligence model was built to analyze real-time data stream to react against the demand. Citizen satisfaction surveys i.e. Net Promoter Score are an established method for public administration to assess the quality of local government services [49].

\subsection{Financial, economic and statistics}

According to Gronroos (1982), service quality is perceived as a result of the service provided by customer service, and the perception is developed through the evaluation of comparison between services. The perceptions of the services are often compared amongst competitors. On the other hand public sector are benchmarked against the response time and the accuracy of the information provided [30]. Table 2 shows big data analytics requirements for public enterprises: service quality.

Table 2. Big data analytics requirements for public enterprises: service quality

\begin{tabular}{|c|c|c|}
\hline Public Enterprises Services Quality & Big Data Analytics area(s) & Research Authors \\
\hline e-Government \& Politics & $\begin{array}{l}\text { online campaign } \\
\text { opinion mining, social \& network } \\
\text { (politic blogs, forums) } \\
\text { e-government service delivery }\end{array}$ & $\begin{array}{l}{[16]} \\
{[33]} \\
{[33],[21]}\end{array}$ \\
\hline Public Health Services & $\begin{array}{l}\text { Administrative, financial } \\
\text { population health monitoring }\end{array}$ & {$[16]-[31]$} \\
\hline Science \& Technology & $\begin{array}{l}\text { Machine learnings data } \\
\text { (astrophysics, oceanography, genomics \& } \\
\text { environment. research) }\end{array}$ & {$[16],[31]$} \\
\hline Security \& Public Safety & $\begin{array}{l}\text { Identity, Sentiment, multimodal } \\
\text { surveillance, cybercrime \& security } \\
\text { intelligence }\end{array}$ & {$[16],[31],[33],[34]$} \\
\hline Financial, Economic \& Statistics & $\begin{array}{l}\text { KPI Dashboard (visualization) } \\
\text { Dynamic Spatial-temporal }\end{array}$ & [34] \\
\hline
\end{tabular}

Large organization, including public enterprise is constantly assessing how to manage volume, variety and velocity of the untapped information in effort to exploit critical decisions [17, 34]. With the current agility requirements real time analytics is required in providing critical insights towards catastrophe advantage. 


\section{CONCLUSION}

Business Intelligence model are used to measure the quality of the service level by using the input data from the Big Data analytics. These measurements on the analytics results can be used as an indicator to measure reliability and accuracy of data quality [39]. The indicators are used to analyze both strengths and weaknesses of Public Enterprise as a whole or within specific service functions [36]. Business intelligence maturity model which has technical stack that should be considered because Big Data Analytics involves large volume, variety and velocity of data, and analyzing theses data requires excellent technology aspect with good implementation of big data warehouse, data quality and understanding of performance management [6].

Author is suggesting the usage of scorecard to benchmark the critical success factor measurement using the performance measurement technique from business intelligence framework. The technical aspect of data warehouse, maturity and data quality determines the quality of service rendered [39]. The model needs additions with new viewpoints on business intelligence, especially from the cultural and enterprise organizational view $[35,36]$. With business intelligence maturity, KPI setters understand the data-structure and behavioral and its relationship of each and every metadata [26, 37]. This determines the capability for user to able to provide insights based on the ability of the user to analyze the data and understand the source of data which provides the behavior of the data, henceforth able to provide detail insight with prediction of the data behavioral [38].

\section{REFERENCES}

[1] AT Kearney. Readiness for the Future of Production Report 2018. Belmont, (CA): World Economic Forum. 2018. pp. $123-135$.

[2] Privacy and Big Data-White Paper [Internet].Schaumburg (USA): ISACA. [updated 13 August 2013; cited 6 Feb 2019]. Available from: http://www.isaca.org/knowledge-center/research/researchdeliverables/pages/privacy-andbig-data.aspx

[3] M Cheryl, HS Jim, N Pierre, P Jonas, C Jean-Yves, S Arne, TV Narendran, D Bob. Digital Transformation Initiative In collaboration with Accenture - Executive Summary January 2017. Belmont, (CA): World Economic Forum. 2017 August. p 10-24. Available from: http://reports.weforum.org/digital-transformation/wpcontent/blogs.dir/94/mp/files/pages/files/170328-dti-executive-summary-slideshare.pdf.

[4] Timothy Hwang. How big and open data can transform Latin America. Belmont, (CA): World Economic Forum. [updated 14 Mar 2018; cited 6 Feb 2019]. Available from: https://www.weforum.org/agenda/2018/03/latinamerica-smart-cities-big-data.

[5] R Antonio. The data made me do it. MIT Technology Review. Cambridge (USA): MIT Technology Review Insights [updated 3 May 2013; cited 6 Feb 2019]. Available from: https://www.technologyreview.com/s/514346/the-data-made-me-do-it/

[6] Manikam S, Sahibudin S, Selamat H. Big Data Analytics Initiatives Using Business Intelligence Maturity Model Approach in Public Sector. Advanced Science Letters. 2017;23(5):4097-4100.. https://doi.org/10.1166/asl.2017.8334

[7] World Economic Forum White Paper Digital Transformation of Industries. Belmont, (CA): World Economic Forum. [updated 10 Jan 2017; cited 6 Feb 2019]. Available from: http://reports.weforum.org/digitaltransformation/wp-content/blogs.dir/94/mp/files/pages/files/digital-enterprise-narrative-final-january-2016.pdf

[8] Country Classification - World Economic Situation and Prospects 2014. New York (USA): United Nations Publications. [updated 7 March 2018; cited 2019 Feb 6]. Available from: http://www.un.org/en/development/desa/policy/wesp/wesp_current/2014wesp_country_classification.pdf

[9] Oracle Cloud. The Convergence of Big Data and the Internet of Thing. Redwood Shores (CA): Oracle White Paper. [updated July 2016; cited 6 Feb 2019]. Available from: http://www.oracle.com/us/solutions/internetofthings/bigdata-and-iot-wp-3098381.pdf

[10] Wo Chang. NIST Big Data Interoperability Framework: Volume 7, Standards Roadmap. Gaithersburg (USA): National Institute of Standards and Technology (NIST) Special Publication 1500-7. http://dx.doi.org/10.6028/NIST.SP.1500-7.

[11] Wo Chang. NIST Big Data Interoperability Framework: Volume 6, Reference Architecture. Gaithersburg (USA): National Institute of Standards and Technology (NIST) Special Publication 1500-6. http://dx.doi.org/10.6028/NIST.SP.1500-6

[12] Wo Chang. NIST Standard Enterprise Big Data Ecosystem. :National Institute of Standards and Technology (NIST). [updated 22 March 2017; cited 6 Feb 2019]. Available from: https://www.iiconsortium.org/pdf/StandardEnterprise-Big-Data-Ecosystem.pdf

[13] Zheng Y, Wang W, Liu W, Mingers J. A performance management framework for the public sector: The balanced stakeholder model. Journal of the Operational Research Society. 2018;:113.https://doi.org/10.1080/01605682.2018.1448247

[14] Liu H, Love P, Smith J, Irani Z, Hajli N, Sing M. From design to operations: a process management life-cycle performance measurement system for Public-Private Partnerships. Production Planning \& Control. 2017;29(1):6883. https://doi.org/10.1080/09537287.2017.1382740 
[15] Wisniewski M, Donnelly M. Measuring service quality in the public sector: the potential for SER VQUAL. Total Quality Management and Business Excellence. 1996 Aug;7(4):357-365. https://doi.org/10.1080/09544129650034710

[16] Economic Planning Unit, Eleventh Malaysia Plan 2016-2020. Percetakan Nasional Malaysia Berhad; 2015. ISBN 978-9675842085

[17] Zikopoulos P. Understanding big data. New York: McGraw-Hill; 2012. ISBN 978-0-07-179053-6

[18] How Malaysia will benefit from TPPA - Nation | The Star Online [Internet]. Thestar.com.my. 2019 [updated 2016 February 4; cited cited 6 February 2019]. Available from: http://www.thestar.com.my/news/nation/2016/02/04/how-malaysia-will-benefit-from-tppa-trade-deal/

[19] Wixom B, Ariyachandra T, Douglas D, Goul M, Gupta B, Iyer L et al. The Current State of Business Intelligence in Academia: The Arrival of Big Data. Communications of the Association for Information Systems. 2014;34. https://doi.org/10.17705/1cais.03401

[20] Zikopoulos P. Understanding big data. New York: McGraw-Hill; 2012. ISBN 978-0-07-179053-6

[21] TDWI Checklist Report | Agile Data Quality: Speed, Flexibility, and Business Alignment for Improving Data | Transforming Data with Intelligence [Internet]. Transforming Data with Intelligence. 2019 [updated 17 June 2013; cited 7 February 2019]. Available from: https://tdwi.org/research/2013/06/tdwi-checklist-report-agile-data-qualityspeed-flexibility-and-business-alignment-for-improving-data.aspx

[22] Abai N, Yahaya J, Deraman A. Incorporating business intelligence and analytics into performance management for the public sector issues and challenges. 2015 International Conference on Electrical /Engineering and Informatics (ICEEI). 2015. https://doi.org/10.1109/ICEEI.2015.7352549

[23] Shi Y, Lu X. The Role of Business Intelligence in Business Performance Management. 2010 3rd International Conference on Information Management, Innovation Management and Industrial Engineering. 2010. https://doi.org/10.1109/ICIII.2010.522

[24] Zakaria Z, Yaacob M, Yaacob Z, Noordin N, Sawal M, Zakaria Z. Key performance indicators (KPIs) in the public sector: A study in Malaysia. Asian Social Science. 2011 Dec 1;7(7):102-107. https://doi.org/10.5539/ass.v7n7p102

[25] Salehi Nasab S, Selamat H, Masrom M. A Delphi Study Of The Important Factors For Bi System Implementation In The Public Sector Organizations. Jurnal Teknologi. 2015;77(19).

[26] Buehler J. Defining Information Needs for Public Health Systems and Services Research. eGEMs (Generating Evidence \& Methods to improve patient outcomes). 2014;2(4):4. http://dx.doi.org/10.13063/2327-9214.1124 Available at: http://repository.academyhealth.org/egems/vol2/iss $4 / 4$

[27] Chen H. Intelligence And Security Informatics for International Security: Information Sharing and Data Mining, New York: Springer. 2006.

[28] Chen H. AI, E-government, and Politics 2.0. IEEE Intelligent Systems. 2009;24(5):64-86.

[29] Herrera F, Sosa R, Delgado T. GeoBI and Big VGI for Crime Analysis and Report. 2015 3rd International Conference on Future Internet of Things and Cloud. 2015. https://doi.org/ 10.1109/FiCloud.2015.112

[30] Chen H. Editorial. ACM Transactions on Management Information Systems. 2011;2(1):1-10. https://doi.acm.org/ $10.1145 / 1929916.1929917$

[31] HJ Watson, BH Wixom, A Thilini. Insights on Hiring for BI and Analytics. Business Intelligence Journal 2013;18(2): 4-5

[32] Zimmer M, Baars H, Kemper H. The Impact of Agility Requirements on Business Intelligence Architectures. 2012 45th Hawaii International Conference on System Sciences. 2012. https://doi.org/ 10.1109/HICSS.2012.567

[33] Raber D, Wortmann F, Winter R. Situational Business Intelligence Maturity Models: An Exploratory Analysis. 2013 46th Hawaii International Conference on System Sciences. 2013. https://doi.org/ 10.1109/HICSS.2013.483

[34] BI Strategy: BI Competency Centers Take Center Stage... Again! | SAP Blogs [Internet]. Blogs.sap.com. 2019 [updated November 2012 ; cited 6 February 2019]. Available from: https://blogs.sap.com/2012/11/07/bi-strategy-bicompetency-centers-take-center-stage-again/

[35] Chuah M, Wong K. An Enterprise Business Intelligence Maturity Model: Case Study Approach. 2013 International Conference on IT Convergence and Security (ICITCS). 2013; https://doi.org/:10.1109/ICITCS.2013.6717802

[36] Gudfinnsson K, Strand M, Berndtsson M. Analyzing business intelligence maturity. Journal of Decision Systems. 2015 Jan 2;24(1):37-54.

[37] Sacu C, Spruit M. BIDM: The Business Intelligence Development Model. Technical Report 2010-010. Institute of Information and Computing Sciences, Utrecht University. 2010

[38] Hribar Rajterič I. Overview of business intelligence maturity models. Management: Journal of Contemporary Management Issues. 2010 Jun 11;15(1):47-67.

[39] Merino J, Caballero I, Rivas B, Serrano M, Piattini M. A data quality in use model for big data. Future Generation Computer Systems. 2016 Oct 1;63:123-30.

[40] G. Inc., Gartner's IT glossary. [Internet]. [updated 2019;cited 6 February 2019]. Available from: http://www.gartner.com/it-glossary/bigdata 2015

[41] ISO, ISO/IEC 25012:2008-Software engineering. Software product quality requirements and evaluation (SQuaRE). Data quality model, Report, International Organization for Standardization. [Internet] [updated December 2008; cited 6 February 2019]. Available from: https://www.iso.org/standard/35736.html

[42] ISO, ISO/IEC CD 25024-Systems and software engineering-Systems and software quality requirements and evaluation (square)-Measurement of data quality, Report, International Organization for Standardization. [Internet] [updated October 2015; cited 6 February 2019]. Available from: https://www.iso.org/standard/35749.html 
[43] Batarseh FA, Latif EA. Assessing the quality of service using Big Data analytics: With application to healthcare. Big Data Research. 2016 Jun 1;4:13-24.

[44] Gonzalez-Alonso P, Vilar R, Lupiáñez-Villanueva F. Meeting Technology and Methodology into Health Big Data Analytics Scenarios. In2017 IEEE 30th International Symposium on Computer-Based Medical Systems (CBMS) 2017 Jun 22 (pp. 284-285). IEEE.

[45] W Raghupathi, V Raghupathi. Big data analytics in healthcare: promise and potential, Heal. Inf. Sci. Syst., 2014;2:3.

[46] L. Fernández-Luque and T. Bau, (2015): Health and social media: Perfect storm of information. Healthc. Inform. Res. 2015;21(2):67-73.

[47] Donald J. Trump for President - CA Political [Internet]. CA Political. 2019 [cited 7 February 2019]. Available from: https://ca-political.com/casestudies/casestudydonaldjtrumpforpresident 2016.

[48] Mokhlis S, Lecturer S. Municipal service quality in southern Thailand: an empirical investigation of customer perceptions. Chief Patron Chief Patron. 2012.

[49] Rodríguez PG, Burguete JL, Vaughan R, Edwards J. The Transformation of Municipal Services: towards Quality in the Public Sector. Theoretical \& Applied Economics. 2009 Feb 1;16(2).

[50] Lee JG, Kang M. Geospatial big data: challenges and opportunities. Big Data Research. 2015 Jun 1;2(2):74-81. 